\title{
Drug Abuse in Zagazig University Students, Egypt: Cross Sectional Study
}

\author{
Dalia M. Amin* (1), Samah A. Elnagdi, Samar A. Amer \\ Forensic Medicine and Clinical Toxicology \& Public Health and Community Medicine Departments, Faculty of Medicine, Zagazig \\ University, Zagazig, Egypt \\ Email: *daliaamin013@gmail.com
}

How to cite this paper: Amin, D.M., Elnagdi, S.A. and Amer, S.A. (2019) Drug Abuse in Zagazig University Students, Egypt: Cross Sectional Study. Occupational Diseases and Environmental Medicine, 7, 37-49.

https://doi.org/10.4236/odem.2019.72004

Received: December 17, 2018

Accepted: March 8, 2019

Published: March 11, 2019

Copyright (c) 2019 by author(s) and Scientific Research Publishing Inc. This work is licensed under the Creative Commons Attribution International License (CC BY 4.0).

http://creativecommons.org/licenses/by/4.0/

\begin{abstract}
Background: Drug addiction is a major public health and socioeconomic problem worldwide that annoys the Egyptian government, as it deals with youth within the age of productivity. Aim of the Work: To determine the prevalence of drug abuse among Zagazig University students. Subjects and Methods: A cross-sectional study conducted on 750 students in Zagazig University from the beginning of November 2015 to the end of November 2016, after an informed verbal consent. Data were collected through a self-administrated questionnaire and the results of screening urine samples. Results: The prevalence of drug abuse in general was $7.41 \%$. The prevalence of drug abuse in descending order was tetrahydrocannabinol (3.9\%) followed by tramadol $(1.9 \%)$ then benzodiazepines $(0.67 \%)$, while, opium and barbiturates each one of them (0.47\%). $18 \%$ of them were Polydrug users and were only males. Tramadol was the commonest drug to use in polydrug users. The prevalence of smoking was $16.81 \%$ and strongly related to gender as in males $26.1 \%$ were current smokers while in females only $1.4 \%$. The prevalence of abusing alcohols was $6 \%$, and all of them were males. Conclusion: The prevalence of drug abuse in Zagazig university students is considered high and a very serious problem damaging the youth and the community. Recommendation: Future longitudinal studies should be conducted to investigate the risk factors of drug abuse and suggest the use of urine analysis for drugs of abuse for all students before joining the university.
\end{abstract}

\section{Keywords}

Abuse, Addiction, Students

\section{Introduction}

Young adulthood, aged 15 - 24, is a period of rapid economic, social, and cultur- 
al transitions in Egypt which have created a favorable condition for increased socially disruptive pattern of drugs and alcohol use. Substance abuse is a growing problem in Egypt, as in many developing countries [1].

In Egypt, university students are very an important category that is liable to depend on the drugs. This is a very serious problem that worries both the people and government; however, data on drug dependence are still few [2]. Very few surveys have reported the incidence of misuse and dependency on substances among these students [3].

Young adults aged 15 - 24 years constituted about $20 \%$ of the population in Egypt in 2000 [4]. Hence, we must pay attention toward the younger age of drug abusers and the increase in the discovery of some of drug abuse with the progressive poisoning pattern over years [5].

The aim of this work is to determine the prevalence of drug abuse among Zagazig university students.

\section{Subjects and Methods}

A cross-sectional study was conducted on Zagazig university students of both sexes, without any mental or psychological or medical disorders, and agreed to participate after a written informed consent, from November 2015 to November 2016.

The sample size was calculated using Open Epi-I program to be 750 stratified random sample weighted according to the students number from both sexes. The students selected from theoretical colleges (e.g. Commerce College and Law College), and Practical colleges (e.g. Medicine, Pharmacy, Science and Nursing College). The Ethical Committee of Zagazig medicine faculty approved the study.

A recoded, pre-tested, well-structured self-administrated questionnaire was used and verified for internal consistency. The questionnaire composed mainly of three parts; sociodemographic data, types of abused drugs and history of previous failure (Annex I model).

Urine samples were screened by dipstick test named $\left(\mathrm{ABON}^{\mathrm{m}}\right.$ Multi-Drug) which is one step screening test panel (Figures 1-3) (used for qualitative detection of drugs of misuse which includes tramadol, opiate, tetrahydrocannabinol, amphetamine, Cocaine, barbiturate, and benzodiazepines). Only positive cases were confirmed by gas chromatography.

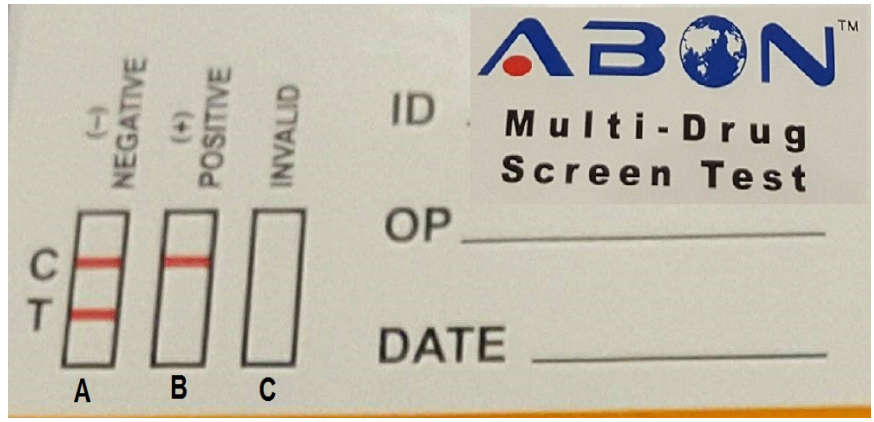

Figure 1. Interpretation of urine screening test: (A) negative, (B) positive, and (C) invalid test. 


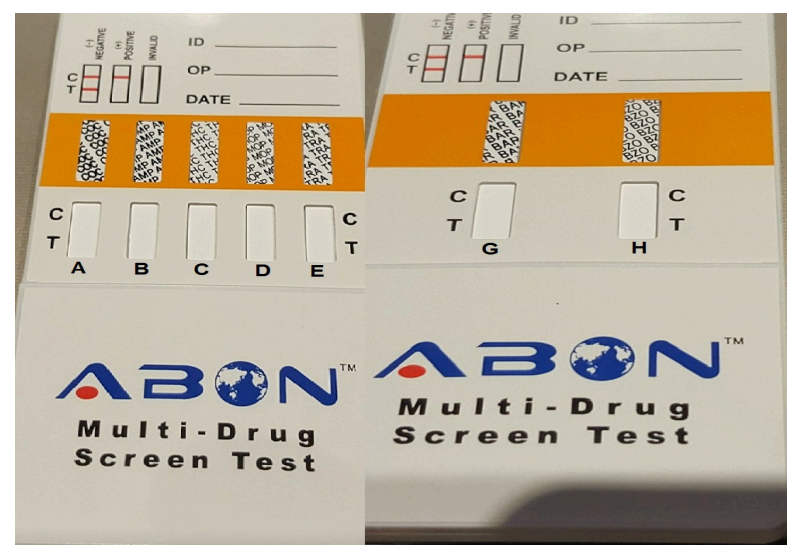

Figure 2. Drug detected by urine screening test: (A) cocaine, (B) amphetamine, (C) THC, (D) opioid, (E) tramadol, (F) barbiturate and (H) benzodiazepine.

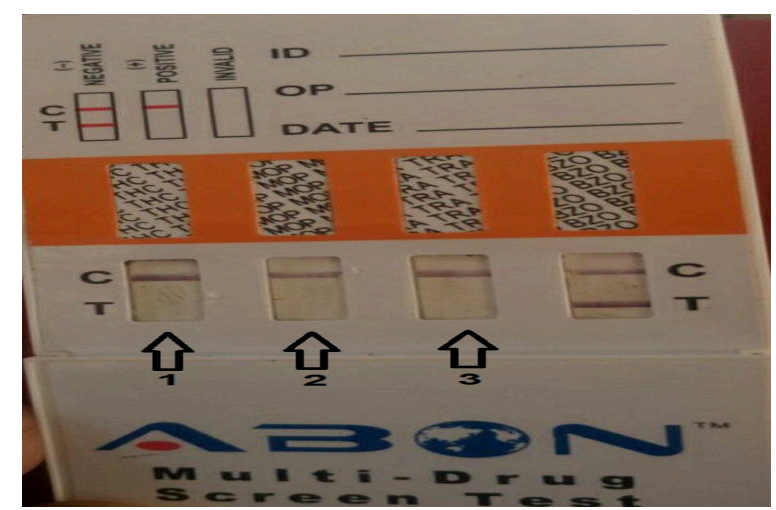

Figure 3. Positive test for TCH (arrow 1), opioide (arrow 2) and tramadol (arrow 3).

The collected data were statistically analyzed using Statistical Package for the Social Science version 16 program. Descriptive statistics were calculated using (frequency, percentage, mean and standard deviation (SD). For analysis of qualitative data, Chi-square test. And fisher exact $\mathrm{t}$ test was used. $\mathrm{P}$ value was considered significant if it was $<0.05$.

\section{Results}

The majority of studied students were males $62.4 \%$, and 37.65 were females. Their mean age was $20.0 \mathrm{yr}$. and 1.31 (SD) that distributed at the following groups in descending order; $52 \%$ were ( $>19-20 \mathrm{y}$ ), 35\% were ( $>21-22 \mathrm{y}$ ), $10.2 \%$ were ( $>17-18 \mathrm{y}$ ), and only $2.8 \%$ were $(>23-24$ y) (Figure 4 ).

$16.8 \%$ of students were smokers, smoking prevalence significantly higher in males (26.1) than females (1.4\%). The prevalence of analgesic misuse was $69.2 \%$, and showed no significant difference as regard sex (males 64.9\%, females 73.9\%). About $10 \%$ of the students stated drinking alcohol, and showed highly significant increase in males $16.5 \%$ with only $6.5 \%$ drank alcohol once, while no females were alcohol abusers. On the other hand, prevalence of sedative misuse was $5.2 \%$ but there was no significant difference between males (5.2\%), and females (5.2\%). $4 \%$ of students misused stimulants without significant differences 
between males (6.5\%) and females (1.25\%) (Table 1).

There was significant increase in prevalence of misusing drugs \& alcohol among smokers than non-smokers. $44.21 \%$ of alcoholic were smokers while $3.6 \%$ were non-smokers. Also $19.79 \%$ of students misusing sedatives were smokers while only $3.25 \%$ of were non-smoker. Regarding stimulants abuse, $23.68 \%$ were smokers while $2.38 \%$ of were non-smokers (Table 2 ).

$18 \%$ of students were polydrug users (Figure 5 ). The percentages of positively screened students were $3.9 \%, 1.9 \%, 0.67 \%, 0.47 \%$ and $0.47 \%$ for tetrahydrocannabinol, tramadol, Benzodiazepine, opium and barbiturates while, there was negative screening for the amphetamin and cocaine. There was significant relationships to sex with $11.67 \%$ of positive screening were males and only $0.84 \%$ were females (Table 3).

There was an association between drug abuse and failure in the exam. There was significant difference between positively screened students failed and unfailed in the exam before (21.05\% and 3.3\% respectively) (Table 4 ).

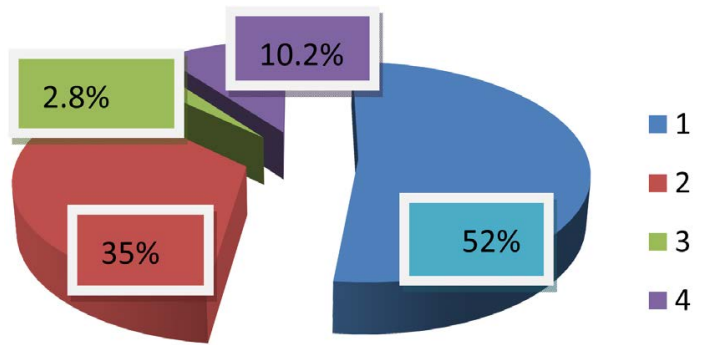

Figure 4. Age distribution among studied students (19 - 20), 2 (21 - 22), 3 (23 - 24) and 4 $(17-18)$.

Table 1. Prevalence of Smoking and substance misuse and its relationship to gender among students in Zagazig University (2016-2017).

\begin{tabular}{lcccc}
\hline & $\begin{array}{c}\text { Males } \\
\text { N }=469 \mathrm{~F}(\%)\end{array}$ & $\begin{array}{c}\text { Females } \\
\mathbf{N}=\mathbf{2 8 2} \mathbf{F}(\%)\end{array}$ & Total (\%) & P value \\
\hline Smoking & $122(26.1)$ & $2(1.4)$ & $(16.5)$ & $<0.0001^{*}$ \\
Analgesics & & & & \\
- Yes & $304(46.9)$ & $209(74.1)$ & 69.2 & 0.08 \\
- No & $123(26.3)$ & $51(18.8)$ & 22.6 & \\
- Once & $41(8.8)$ & $22(7.7)$ & 8.2 & \\
Alcohol & & & & \\
- Yes & $78(16.7)$ & $0(0.0)$ & 10.3 & \\
- No & $359(76.1)$ & $(97.9) 276$ & 89.6 & \\
- Once & $31(6.6)$ & $6(2.1)$ & 4.4 & \\
Sedatives & & & & \\
- Yes & $25(5.3)$ & $15(5.3)$ & 5.2 & \\
- No & $430(91.9)$ & $261(92.7)$ & 93.7 & \\
- Once & $13(2.8)$ & $6(2.1)$ & 1.1 & \\
Stimulant & & & & \\
- Yes & $30(6.4)$ & $4(1.4)$ & 4 & \\
- No & $431(92.1)$ & $274(97.2)$ & 94.6 & \\
- Once & $7(1.5)$ & $4(1.4)$ & 1.4 & \\
\hline
\end{tabular}

*Significant. 


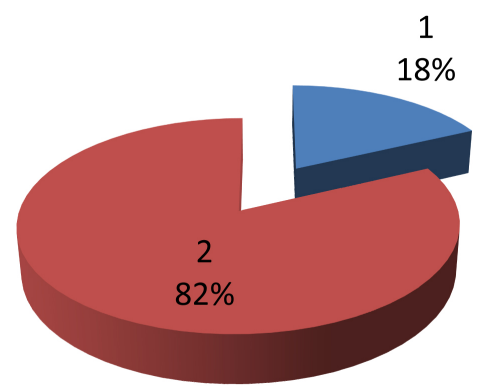

Figure 5. Percentage of polydrug users among the positive studied population.

Table 2. Percentage of abusing sedatives, stimulants and alcohols in relation to smoking among 750 students in Zagazig University (2016-2017).

\begin{tabular}{ccccc}
\hline $\begin{array}{c}\text { Substance } \\
\text { Abused }\end{array}$ & $\begin{array}{c}\text { Smoker } \\
\mathrm{N}=\mathbf{5 7 ~ F ~ ( \% )}\end{array}$ & $\begin{array}{c}\text { Non-smoker } \\
\mathrm{N}=6 \mathbf{6 3}(\%) \mathrm{F}(\%)\end{array}$ & Total (\%) & P value \\
\hline Alcohols & $32(56.1)$ & $26(3.8)$ & $6.6)$ & $<0.0001^{*}$ \\
Sedatives & $11(19.3)$ & $23(3.3)$ & $4.52)$ & $<0.0001^{*}$ \\
Stimulants & $14(24.6)$ & $16(2.3)$ & $4.0)$ & $<0.0001^{*}$ \\
\hline
\end{tabular}

*Significant.

Table 3. Positive urine screening test results and its relationship to sex among studied Zagazig university students (2016-2017).

\begin{tabular}{ccccc}
\hline Drug screened & $\begin{array}{c}\text { Males } \\
\mathbf{N}=468 \mathrm{~F}(\%)\end{array}$ & $\begin{array}{c}\text { Females } \\
\mathbf{N}=282 \mathrm{~F}(\%)\end{array}$ & Total \% & P value \\
\hline THC & $30(6.4)$ & 0 & 3.9 & $<0.0001^{*}$ \\
Tramadol & $16(3.4)$ & $1(0.35)$ & 1.9 & 0.02 \\
BZDs & $4(0.85)$ & $1(0.35)$ & 0.67 & 0.62 \\
Opium & $4(0.85)$ & 0 & 0.47 & 0.18 \\
Barbiturates & $4(0.85)$ & 0 & 0.47 & 0.18 \\
Amphetamine & 0 & 0 & 0 & 0 \\
Cocaine & 0 & 0 & 0 & 0 \\
All drugs & $54(11.5)$ & $2(0.71)$ & 7.41 & $<0.0001^{*}$ \\
\hline
\end{tabular}

*Significant; THC $=$ Tetrahydrocannabinol; BZDs = Benzodiazepine.

Table 4. Relationship between positive urine screening results and previous failure history in exams among students in Zagazig University (2016-2017).

\begin{tabular}{ccccc}
\hline $\begin{array}{c}\text { Failed in an } \\
\text { exam before }\end{array}$ & $\begin{array}{c}\text { Yes } \\
\text { N }=114 \mathrm{~F}(\%)\end{array}$ & $\begin{array}{c}\text { No } \\
\mathbf{N}=636 \mathrm{~F} \mathrm{( \% )}\end{array}$ & Total \% & P value \\
\hline THC (\%) & $9(7.89)$ & $12(1.89)$ & 1.19 & $0.003^{*}$ \\
Tramadol (\%) & $7(6.1)$ & $6(0.94)$ & 1 & $0.001^{*}$ \\
Opium (\%) & $2(1.8)$ & $2(0.31)$ & 0.2 & 0.17 \\
BDZs (\%) & $3(2.63)$ & $2(0.31)$ & 0.39 & $0.001^{*}$ \\
Barbiturates (\%) & $3(2.63)$ & 0.00 & 0.39 & $0.001^{\star}$ \\
All drugs & $24(21.05)$ & $21(3.3)$ & 3.17 & $<0.0001^{\star}$
\end{tabular}

${ }^{*}$ Significant; THC = Tetrahydrocannabinol; BZDs = Benzodiazepine. 


\section{Discussion}

Drug addiction is a major public health and socioeconomic problem worldwide that annoys the Egyptian government. This study was done to determine the prevalence of drug misuse among Zagazig University students.

In this study, the mean age of the studied students was $20.03 \pm 1.31$ years similar to mean age declared by Bethany et al. (2013) [6] in adolescents admitted for substance use disorder treatment in the northeastern United States medical centers and Nahid et al. (2014) [7] in Students of Isfahan Province, Iran who found that the mean age of students in their samples was 20.9, 19.6 years, respectively.

In contrary Hamdi et al. (2013) [8] studied that students from 8 governorates in Egypt showed the highest onset of substance use at age of 15 years old, because of the demographic pattern that reflects availability and accessibility to drugs.

Smoking prevalence was $16.81 \%$ conducted by Refaat (2004) [9] among Suez Canal University students, who reported current smoker prevalence was $26.5 \%$ in males, $12.2 \%$ in females. Radwan et al. (2015) [10] found that current smokers in males were about $27.5 \%$ and in females about $18.1 \%$ in the Egyptian national survey.

Smoking prevalence was significantly higher in males $(26.1 \%)$ than females $(1.4 \%)$. These results are in agreement with the study that stated that prevalence of smoking was higher among males than females. This is because of the cultural and social traditions in Egypt [11].

The prevalence of analgesic misuse was $69.2 \%$ (males $64.9 \%$ and females 73.9\%). These results are approximately similar to an Iranian study conducted by Sarahroodi et al. (2012) [12] who found that $76.6 \%$ of the respondents reported using analgesics with $73.4 \%$ male and $79.2 \%$ female students.

Mc-Cabe et al. (2008) [13] in the United States found that 54.3\% of students reported using analgesics and $9.7 \%$ of students reported taking stimulants in their lifetime.

The alcohol prevalence was $10.29 \%$. This is in an agreement with Karam et al. (2007) [14] who found that the alcohol prevalence was $10.5 \%$. In contrary Tesfaye (2014) [15] reported that $50.2 \%$ drank alcohol at least once in their lifetime from them $53.8 \%$ in males and $38.8 \%$ in females in Ethiopia. This was explained by Biratu et al. (2014) [16] who stated that homemade alcoholic drinks are acceptable for the vast majority of Ethiopian people. Furthermore, Yuri et al. (2011) [17] at the Federal University of Alagoas reported that regular alcohol prevalence was $29.1 \%$.

The prevalence of sedative misuse among studied students was $5.2 \%$. Iranian study conducted by Rezahosseini et al. (2014) [18] found that the prevalence of sedatives was 7.4\%, while Ahmed et al. (2014) found that 17\% of students reported taking sedative in the King Saud University Medical Students.

In this study the prevalence of stimulant misuse among studied students was 4\% higher than a study done by Mohamed et al. (2007) [19] in Zagazig Univer- 
sity who found that $1.30 \%$ of students were abusing stimulants as the awareness by abusing drugs increase.

Also, there were significant difference between smokers misusing drugs \& alcohol and non-smoker misusing them. Katie et al. (2012) [20] identified that there was a strong association between drinking alcohol and smoking among college students. Reed et al. (2007) [21] reported that students tend to smoke more cigarettes when they were drinking.

In a study done on college students' attitudes about smoking Dierker et al. (2006) [22] found that the primary reason for starting to smoke, and the main reason smokers continue to smoke as reported were addiction and stress.

Similarly, in a self-administered questionnaire study among 3258 students at 11 faculties of Assiut University El-Ansari et al. (2014) [23] found that drinking alcohols was positively associated with one's illicit drug/s use.

The most abused drug was tetrahydrocannabinol followed by tramadol then benzodiazepines, while opium and barbiturates in the same category. These were in an agreement with Webb (2006) [24] who conducted a study on United Kingdom university students, it had been found that tetrahydrocannabinol was the most common drug abused. This was explained by their families by being common in the locality with relatively low price, followed by tramadol and there was significant relationship between drug abuse and sex (more in males).

In contrary, Adeyemo et al. (2016) [25] reveal that alcohol was the most commonly abused drugs amongst University Students in Benin City, Nigeria. Maria et al. (2015) [26] who conducted a survey on 275 university students in a private institution in Brazil, found that alcohol was the most widely used drug, followed by tobacco, and marijuana then psychoactive drugs.

Mwaheb et al. (2012) [27] conducted a study in Fayom city on male students and found that $75 \%$ of them were abusers of drugs. They reported that the common drugs of abuse were $40 \%$ cannabis, $37 \%$ tramadol, and $23 \%$ benzodiazepine. These percentages are higher than the current study and this may be due to conduction of the study on males only.

In contrary, A North American study entitled "Monitoring the Future" reported the following data regarding the prevalence of drug use by university students over a year: alcohol $(82.1 \%)$, tobacco $(30.0 \%)$, and marijuana $(32.3 \%)$. These are evidence that the high rate of use of alcohol followed by the use of tobacco and marijuana is a reality worldwide and, thus, use of drugs is a global public health issue [28].

In this study, the percentages of positively screened students of all studied population were $3.9 \%, 1.9 \%, 0.67 \%, 0.47 \%$ and $0.47 \%$ for tetrahydrocannabinol, tramadol, Benzodiazepine, opium and barbiturate respectively. On the other hand, there was negative screening for the amphetamin and cocaine.

Regarding screening for drug of abuse, El-Ezz and Ez-Elarab (2011) [29] in Ain Shams University found that $87.2 \%, 12 \%$ and $3.3 \%$ of students were abused on analgesics, sedatives and stimulants respectively. 
Negative amphetamines and cocaine screening results came in agreement with a study conducted by Werese and Hambisa (2014) [30] in Ethiopia and Goreishi and Shajari (2013) [31] in Iranian study.

There was strong association between positively screened students and failure in the exams before. Similarly, a study in Colombia concluded that drug abuse was a major problem and the main cause in university students reported a higher default and dropout, school dissatisfaction, a higher amount of repetitions in the courses and low academic performance [32].

Tarig et al. (2016) [33] carried a study in Sudan university students and found that Curiosity (33.1\%) was the main reason for initiation of substance abuse.

Strength: The first study of this kind in Zagazig University students. It is a large population-based study that involves at-risk groups (adolescents and young adults). It includes the prevalence of many drug misuses.

\section{Limitation}

Despite cross-sectional studies can usually be conducted relatively faster and are inexpensive, but large scale studies are needed to predict incidences. The study also is prone to certain biases because of the students response (recall and stigma) enrolled in. The lab results may be affected by the time of the sample collection.

\section{Recommendation}

Future longitudinal studies are recommended to be conducted to investigate the risk factors of drug abuse and suggest use of urine analysis for drugs of abuse for all students before joining the university.

\section{Conflicts of Interest}

The authors declare no conflicts of interest regarding the publication of this paper.

\section{References}

[1] Hamedi, E., Sabry, N., Sedrak, A., Khowailed, A. and Loza, N. (2016) Sociodemographic Indicators for Substance Use and Abuse in Egypt. Journal of Addiction \& Prevention, 4, 8.

[2] El-Sawy, H., Hay, M.A. and Badawy, A. (2010) Gender Differences in Risks and Pattern of Drug Abuse in Egypt. Egyptian Journal of Neurology, Psychiatry and Neurosurgery, 47, 413-418.

[3] Monirpoor, N., Khoosfi, H., Gholamy, M., Tamaddonfard, M., Tabatabaei, S.F. and Mohammad, (2014) Vulnerability to Substance Abuse and the Risk of Suicide in Students of Region 12 of Islamic Azad University. International Journal of High Risk Behaviors and Addiction, 3, 111-122. https://doi.org/10.5812/ijhrba.11229

[4] Refaat, D. (2004) Stages in Adolescent Involvement in Drug Use. SCIE, 190, 912-914.

[5] El-Masry, M.K. and Tawfik, H.M. (2013) Annual Report of the Poison Control 
Centre of Ain Shams University Hospital, Cairo, Egypt. Ain Shams Journal of Forensic Medicine and Clinical Toxicology, 20, 10-17. https://doi.org/10.21608/ajfm.2013.19382

[6] Bethany, K.B., John, R. and Kevin, P. (2013) Sex, Age, and Progression of Drug Use in Adolescents Admitted for Substance Use Disorder Treatment in the Northeastern United States: Comparison with a National Survey. Substance Abuse, 34, 263-272. https://doi.org/10.1080/08897077.2013.770424

[7] Nahid, G., Leila, G., Shohreh, A., Fatemeh, M., Mahmonir, N., Ziba, F. and Kamal, H. (2014) Development of a Questionnaire to Assess Drug Abuse among High School Students of Isfahan Province, Iran: An Action Research. International Journal of Preventive Medicine, 5, 146-153. https://doi.org/10.4103/2008-7802.157678

[8] Hamdi, E., Gawad, T., Khoweiled, A., Sidrak, A.E., Amer, D., Mamdouh, R., Fathi, H. and Loza, N. (2013) Lifetime Prevalence of Alcohol and Substance Use in Egypt: A Community Survey. Substance Abuse, 34, 97-104. https://doi.org/10.1080/08897077.2012.677752

[9] Radwan, G., Eltahlawy, E., El-Setouhy, M., Magder, L. and Hussein, M. (2015) Estimates of the Prevalence of Tobacco Smoking in Egypt. Open Journal of Epidemiology, 5, 129-135. https://doi.org/10.4236/ojepi.2015.52017

[10] Adams, M.L., Jason, L.A., Pokorny, S. and Hunt, Y. (2009) The Relationship between School Policies and Youth Tobacco Use. Journal of School Health, 79, 17-23. https://doi.org/10.1111/j.1746-1561.2008.00369.x

[11] Sarahroodi, S., Maleki-Jamshid, A., Sawalha, A.F., Mikaili, P. and Safaeian, L. (2012) Pattern of Self-Medication with Analgesics among Iranian University Students in Central Iran. Journal of Family \& Community Medicine, 19, 125-129. https://doi.org/10.4103/2230-8229.98302

[12] McCabe, S.E., Teter, C.J. and Boyd, C.J. (2008) Medical Use, Illicit Use and Diversion of Prescription Stimulant Medication. Journal of Psychoactive Drugs, 38, 43-56. https://doi.org/10.1080/02791072.2006.10399827

[13] Karam, E., Kypri, K. and Salamoun, M. (2007) Alcohol Use among College Students: An International Perspective. Current Opinion in Psychiatry, 20, 213-221. https://doi.org/10.1097/YCO.0b013e3280fa836c

[14] Tesfaye, G. (2014) Practice and Awareness of Health Risk Behaviour among Egyptian University Students. Eastern Mediterranean Health Journal, 10, 72-81.

[15] Biratu, A.K., Seyoume, F.T. and Dubi, A.Y. (2014) Prevalence and Factors Determining Psychoactive Substance (PAS) Use among Hawassa University (HU) Undergraduate Students, Hawassa Ethiopia. BMC Public Health, 14, 10-44.

[16] Brandão, Y.S.T., Correia, D.S., de Farias, M.S.J.A., Antunes, T.M.T., da Silva, L.A. (2011) The Prevalence of Alcohol Consumption among the Students Newly Enrolled at a Public University. Journal of Pharmacy and BioAllied Sciences, 3, 345-349. https://doi.org/10.4103/0975-7406.84434

[17] Rezahosseini, O., Roohbakhsh, A., Tavakolian, V. and Assar, S. (2014) Drug Abuse among University Students of Rafsanjan, Iran. Iranian Journal of Psychiatry and Behavioral Sciences, 8, 81-85.

[18] Al-Sayed, A.A., Al-Rashoudi, A.H., Al-Eisa, A.A., Addar, A.M., et al. (2014) Sedative Drug Use among King Saud University Medical Students: A Cross-Sectional Sampling Study. Depression Research and Treatment, 2014, Article ID: 378738. https://doi.org/10.1155/2014/378738

[19] Mohamed, M.B., Abd El-Hammed, E.H., Sherif, N.A. and El-Sharkawy, G.F. (2007) Drug Abuse among Zagazig University Students Prevalence and Risk Factor. Master 
Thesis in Public Health, Zagazig University, Ash Sharqiyah, 158.

[20] Witkiewitz, K., Desai, S.A., Steckler, G., Jackson, K.M., Bowen, S., Leigh, B.C. and Larimer, M.E. (2012) Concurrent Drinking and Smoking among College Students: An Event-Level Analysis. Psychology of Addictive Behaviors, 26, 649-654. https://doi.org/10.1037/a0025363

[21] Reed, M.B., Wang, R., Shillington, A.M., Clapp, J.D. and Lange, J.E. (2007) The Relationship between Alcohol Use and Cigarette Smoking in a Sample of Undergraduate College Students. Addictive Behaviors, 32, 449-464. https://doi.org/10.1016/j.addbeh.2006.05.016

[22] Dierker, L., Lloyd-Richardson, E., Stolar, M., Flay, B., Tiffany, S., Collins, L., et al. (2006) The Proximal Association between Smoking and Alcohol Use among First Year College Students. Drug and Alcohol Dependence, 81, 1-9. https://doi.org/10.1016/j.drugalcdep.2005.05.012

[23] El-Ansari, W., Sebena, R. and Labeeb, S. (2014) Multiple Risk Factors: Prevalence and Correlates of Alcohol, Tobacco and Other Drug (ATOD) Use among University Students in Egypt. Journal of Substance Use, 20, 380-388. https://doi.org/10.3109/14659891.2014.923533

[24] McMillan, B. and Conner, M. (2002) Drug Use and Cognitions about Drug Use amongst Students: Changes over the University Career. Journal of Youth and Adolescence, 31, 221-229. https://doi.org/10.1023/A:1015037319936

[25] Adeyemo Florence, O., Beatrice, O., Okpala, P.U. and Oghale, O. (2016) Prevalence of Drug Abuse amongst University Students in Benin City, Nigeria. Public Health Research, 6, 31-37.

[26] Zeferino, M.T., Hamilton, H., Brands, B., da Glória Miotto Wright, M., Cumsille, F. and Khenti, A. (2015) Drug Consumption among University Students: Family, Spirituality and Entertainment Moderating Influence of Pairs. Texto \& Contexto-Enfermagem, 24, 125-135. https://doi.org/10.1590/0104-07072015001150014

[27] Mwaheb, M.A., El-Galad, G.M., Dawood, A.A. and El-sayed, S.H. (2012) Drug Abuse among Students in (Schools and Colleges) in Fayoum City. MD Thesis, Forensic Medicine and Clinical Toxicology, Fayoum University, Fayoum, 274.

[28] Alvarez, J., Jason, L.A., Olson, B.D., Ferrari, J.R. and Davis, M.I. (2007) Substance Abuse Prevalence and Treatment among Latinos and Latinas. Journal of Ethnicity in Substance Abuse, 6, 115-141. https://doi.org/10.1300/J233v06n02_08

[29] El-Ezz, N.F. and Ez-Elarab, H.S. (2011) Knowledge, Attitude and Practice of Medical Students towards Self Medication at Ain Shams University, Egypt. Journal of Preventive Medicine and Hygiene, 52, 196-200.

[30] Tesfaye, G., Derese, A. and Hambisa, M.T. (2014) Substance Use and Associated Factors among University Students in Ethiopia: A Cross-Sectional Study. Journal of Addiction, 2014, Article ID: 969837. https://doi.org/10.1155/2014/969837

[31] Goreishi, A. and Shajari, Z. (2013) Substance Abuse among Students of Zanjan's Universities (Iran): A Knot of Today's Society. Addiction \& Health, 5, 66-72.

[32] Castaño-Perez, G.A. and Calderon-Vallejo, G.A. (2014) Problems Associated with Alcohol Consumption by University Students. Revista Latino-Americana de Enfermagem, 22, 739-46. https://doi.org/10.1590/0104-1169.3579.2475

[33] Osman, T., Victor, C., Abdulmoneim, A., Mohammed, H., Abdalla, F., Ahmed, A., Ali, E. and Mohammed, W. (2016) Epidemiology of Substance Use among University Students in Sudan. Journal of Addiction, 2016, Article ID: 2476164.

https://doi.org/10.1155/2016/2476164 


\section{Arabic Abstract}

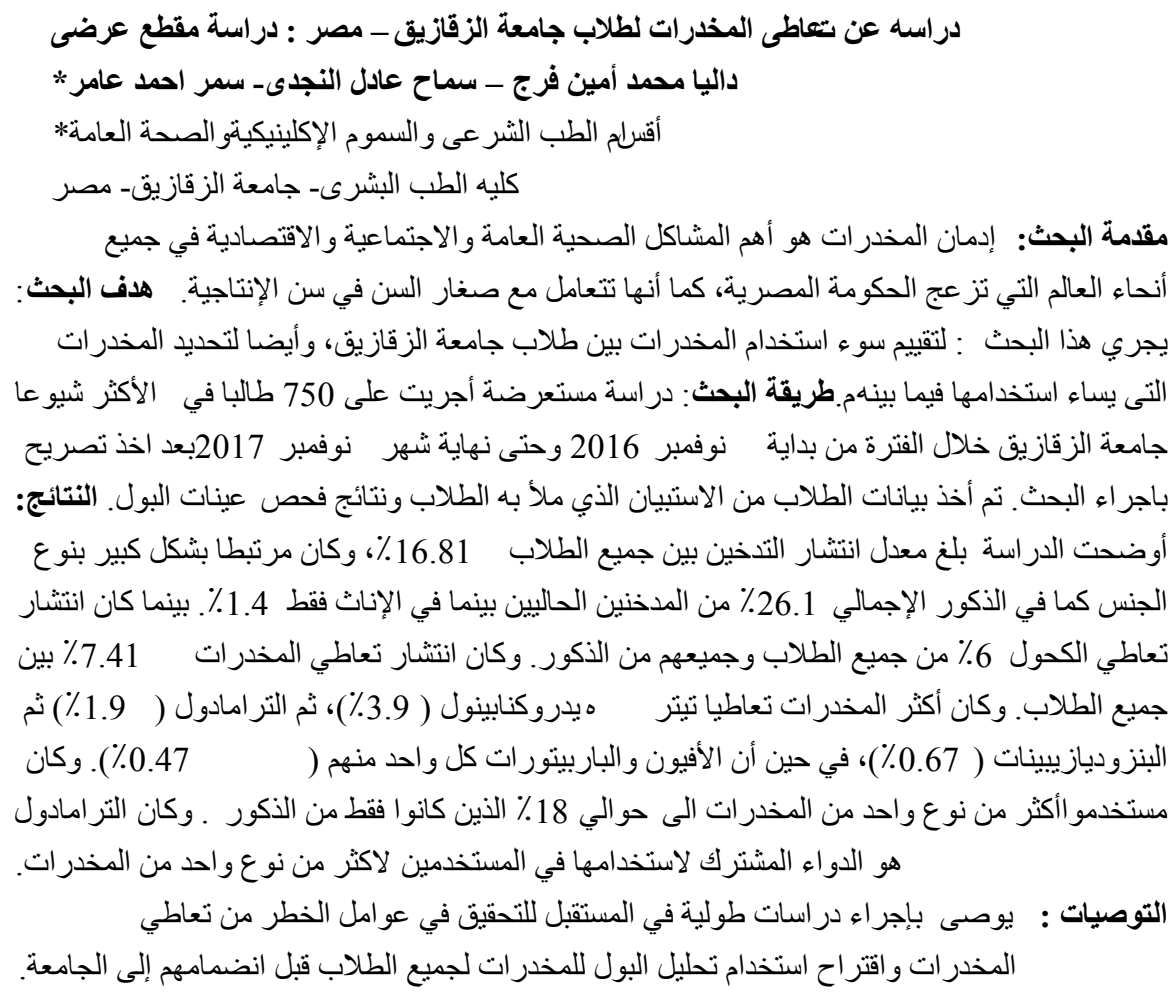

\section{Annex I Model Student Questionnaire}

These questions refer to the past 12 months.

\section{Circle your response}

1 -What is your sex?

Male

Female

2-In what year were you born? Year

3-Have you used drugs other than those required for medical reasons?

Yes No

4-Have you abused prescription drugs?

Yes

No

5 -Do you abuse more than one drug at a time?

Yes

No

6-Can you get through the week without using drugs?

Yes

No

7-Are you always able to stop using drugs when you want to?

Yes

No

8-How frequently have you smoked cigarettes during the LAST 30 DAYS? Not at all yes No

9-How frequently have you drunk alcoholic beverage to drink (more than just a few sips)?

Not at all 
_ yes

_ No

10-Have you ever heard of any of the following drugs?

Yes

No

(a) Tranquillizers or sedatives [give names that apply]

(b) Marijuana (grass, pot) or hashish (hash, hash oil)

(c) Amphetamines (uppers, pep pills, bennies, speed)

(d) Ecstasy

(e) LSD

(g) Crack

(h) Cocaine

(i) Heroin

(j) tramadol

11-How many times IN YOUR LIFE (if any) have you used any of the following drugs?

Not at all

Yes

No

(a) Marijuana (grass, pot) or hashish (hash, hash oil)

(b) Tranquillizers or sedatives

(c) Amphetamines (speed)

*(d) Methamphetamine

(e) Ecstasy

(f) LSD

(i) Cocaine

(j) Crack

(k) Heroin (smack, horse)

(l) Other opiates (tramadol)

12-Did you fail in the exame before?

Yes

No

13-Do you ever feel bad or guilty about your drug use?

Yes

No

14-Does your spouse (or parents) ever complain about your involvement with drugs?

Yes

No

15-Has drug abuse created problems between you and your spouse or your parents?

Yes

No

16-Have you lost friends because of your use of drugs?

Yes

No

17-Have you neglected your family because of your use of drugs?

Yes

No

18-Have you been in trouble at work because of drug abuse?

Yes

No

19-Have you lost a job because of drug abuse? 
Yes

No

20-Have you gotten into fights when under the influence of drugs?

Yes No

21-Have you engaged in illegal activities in order to obtain drugs?

Yes

No

22-Have you been arrested for possession of illegal drugs?

Yes No

23-Have you ever experienced withdrawal symptoms (felt sick) when you stopped taking drugs?

Yes No

24-Have you had medical problems as a result of your drug use (e.g. memory loss, hepatitis, convulsions, bleeding, etc.)?

Yes

No

25-Have you gone to anyone for help for a drug problem?

Yes No

26-Have you been involved in a treatment program specifically related to drug use?

Yes

No

27-What is your father and mother job?

28-What is your father and your mother education?

29-How many person per sleeping room? 